\title{
HISTÓRIA DAS ORIGENS DO MOVIMENTO DE MULHERES CAMPONESAS DO PARANÁ (1981-2016)
}

\author{
HISTORY OF WOMEN'S PEASANT ORIGINS \\ MOVEMENT OF PARANA (1981-2016)
}

\begin{abstract}
Resumo
O objetivo deste trabalho é resgatar as origens do Movimento de Mulheres Camponesas do Paraná (MMC/PR), sua trajetória, até se consolidar como MMC/PR. Compreendemos que é muito relevante que as histórias dos movimentos sociais sejam mantidas, como uma forma de conscientizar sobre os processos de conquista de direitos e também como um meio de inspirar mais militantes e manter os movimentos vivos e fortalecidos. Torna-se mais importante quando se trata de um movimento de mulheres, já que vivemos ainda em uma sociedade regida por valores patriarcais que discriminam e oprimem as mulheres. Para a realização desta pesquisa foram feitas entrevistas com três dirigentes do MMC/PR e uma de SC, além de consulta a materiais bibliográficos do próprio MMC e suas articulações anteriores e de outros livros e artigos relacionados ao tema estudado.
\end{abstract}

Palavras-chave: Movimentos Sociais. Feminismos. MMC/PR.

\begin{abstract}
The objective of this work is to rescue the origins of the Women's Peasant Origins Movement of Parana (MMC / PR), its trajectory, to consolidate as MMC / PR. We understand that it is very important that the stories of social movements are maintained, as a way to raise awareness of the achievement process rights and also as a means to inspire more militants and keep alive and strengthened movements. It becomes more important when it comes to a women's movement, as we still live in a society governed by patriarchal values that discriminate against and oppress women. To carry out this research were made interviews with three directors of MMC / PR and SC, as well as consulting bibliographic materials MMC and its own previous joints and other books and articles related to the subject studied.
\end{abstract}

Keywords: Social Movements. Feminisms. MMC/PR.

\section{Renata R. Gadelha}

Mestra pelo Programa de Pós-Graduação em Agroecologia e Desenvolvimento Rural Sustentável da Universidade da Fronteira Sul (UFFS).

E-mail: regadelha@hotmail.com

\section{Sandra M. R. Rodrigues}

Graduada em Pedagogia para Educadores do Campo, Mestranda do Programa de Pós-Graduação Stricto Sensu - Sociedade, Cultura

e Fronteiras, UNIOESTE Campus Foz do Iguaçu.

E-mail: darocharodrigues@gmail.com

Siomara A. Marques

Professora Doutora em Sociologia pela UFSC, Universidade Federal da Fronteira Sul (UFFS).

E-mail: siomarques@uffs.edu.br

Antônio I. Andrioli

Professor Pós-Doutor pela Universidade Johannes Kepler de Linz/Áustria, Universidade Federal da Fronteira Sul (UFFS).

E-mail: gabinete@uffs.edu.br 


\section{Introdução}

Resgatar a história dos movimentos sociais é tarefa essencial para que possamos compreender nossa realidade atual, de como nossos direitos foram conquistados. Compreender as lutas que foram travadas e todo o processo de construção dessas lutas nos revela que nenhum direito, transformação social, ocorre se não nos mobilizamos e organizamos socialmente. Conservar viva as histórias de lutas é uma arma para que as gerações futuras compreendam que as vitórias contra a discriminação e exploração em nossa sociedade foram feitas à custa de muito esforço, organização e resistência. Dessa forma, a história, mais que revelar faces ocultas de nossa realidade cotidiana, inspira, fortalece e forma tantos outros sujeitos que se conscientizam que não só podem, mas devem, ser os sujeitos de sua própria história.

Quando se trata de resgatar a história da luta das mulheres, essa tarefa se torna ainda mais importante. Tendo em vista que, vivemos em uma sociedade patriarcal que avalia, julga e age com olhos e de forma androcêntrica no mundo, perpetuando diversas discriminações, opressões e explorações contra a mulher, resgatar a história de luta das mulheres é resgatar sua força, sua autonomia e os processos através dos quais elas começam a se tornar sujeitos de si.

Em nossas pesquisas não conseguimos encontrar nenhum trabalho que nos contasse a história de luta das mulheres trabalhadoras rurais no Paraná até a formação do atual Movimento de Mulheres Camponesas. Nesse sentido, se mostrou necessário resgatar essa história, essa trajetória que vai culminar no que é hoje o MMC no estado do Paraná, e este é o objetivo deste trabalho.

Para a realização desta pesquisa foram feitas entrevistas com três dirigentes do $\mathrm{MMC} / \mathrm{PR}$ e uma do $\mathrm{MMC} / \mathrm{SC}$, assim como, consultas bibliográficas do acervo do MMC e de outros livros e artigos que tratavam sobre o assunto.

\section{Elementos que influenciaram no surgimento dos Movimentos de Mulheres do Campo}

Para compreendermos melhor o surgimento dos movimentos sociais de mulheres do campo, sua luta contra as discriminações de gênero e sobre sua preocupação com a devastação do ambiente, seria importante, antes, fazermos um breve resgate histórico das condições políticas e sociais, a partir das quais vão surgir esses movimentos.

Esses movimentos surgem como resposta à tentativa do Estado de colocar em prática no país um modelo de desenvolvimento excludente. $\mathrm{Na}$ segunda metade do século XX o governo brasileiro adotou uma concepção de desenvolvimento, como se esse fosse sinônimo de crescimento econômico. Buscavase uma solução mecânica para os problemas sociais e ambientais: uma vez que os países aumentassem seu produto interno bruto per capita isso resultaria num desenvolvimento não só econômico, como também social e ambiental da sociedade (qualidade de vida, recuperação dos danos ambientais, etc.) (FURTADO, 2000; VEIGA, 2006). Nesse sentido, Furtado defende a posição de que a noção de desenvolvimento econômico não passa de um mito. Esse mito apenas teria a função de:

\begin{abstract}
Mobilizar os povos da periferia e levá-los a aceitar enormes sacrifícios para legitimar a destruição de formas de culturas arcaicas, para explicar e fazer compreender a necessidade de destruir o meio físico, para justificar formas de dependência que reforçam o caráter predatório do sistema produtivo FURTADO, 2000, p. 89) [destaques do autor].
\end{abstract}

No Brasil a concepção "desenvolvimento como crescimento econômico" advém de um contexto histórico nacional onde se buscava fomentar a industrialização, a urbanização e a modernização do campo. Segundo Furtado (2000), quando surge o conceito de "sistema econômico nacional" (como reação à doutrina do livre cambismo $^{1}$ ), o significado de desenvolvimento passa a ser vinculado à ideia de "interesse nacional". O Estado tem a responsabilidade de orientar as atividades econômicas. Todavia, Estados tão dependentes/

1 Livre cambismo é um modelo de mercado no qual a troca de bens e serviços entre países não é afetada por restrições do estado. É o contrário de protecionismo, que é a política econômica que pretende restringir o comércio entre países. As trocas podem ser restringidas pela aplicação de taxas e tarifas alfandegárias, etc.; esta política econômica visa proteger a indústria nacional em detrimento da concorrência estrangeira. 
endividados, como os dos países em industrialização, acabaram sendo coordenados pelas exigências dos Estados credores através da criação da superestrutura institucional: Fundo Monetário Internacional (FMI), Banco Mundial e Acordo Geral de Tarifas e Comércio (GATT). Tendo isso em vista, Furtado (2000) define o subdesenvolvimento como sendo a: "conformação de sociedades em que relações externas assimétricas, que geram dependência, articulam-se internamente com o sistema de dominação social" (Ibid, ibidem, p. 49).

Todavia este autor não chega à raiz do problema, pois não questiona o próprio modo de produção capitalista. Se partirmos de uma perspectiva marxista, os problemas seriam explicados de outra forma: não é o subdesenvolvimento que gera a pobreza, mas sim o próprio sistema capitalista que gera tanto o subdesenvolvimento, como a pobreza. São as relações que os seres humanos estabelecem entre si que condicionam a produção e a reprodução da riqueza e da pobreza nas sociedades. A pobreza é o resultado do nível e da distribuição de recursos na sociedade. No capitalismo, o avanço das forças produtivas que gerou maior excedente econômico, não levou ao bem-estar do conjunto da população. A urbanização e industrialização promoveram elevação da capacidade produtiva (aumento do produto interno bruto e da renda per capita), mas intensificou a pobreza (CAMPOS, 2011, p. 52).

A própria lógica do capital faz com que a sociedade gere uma massa de marginalizados, sem empregos ou com subempregos. Pois, como a meta é sempre a do lucro e a da acumulação de capital, buscase continuamente reduzir os custos de produção, logo, criam-se estratégias ou de substituir o trabalho humano por máquinas, ou de gerar empregos precários, com baixos salários e sem direitos.

O Brasil invadido pelos portugueses se forma dentro do modo de produção capitalista. Sua estrutura fundiária estava e está baseada no latifúndio, fonte da concentração da riqueza e das desigualdades sociais em nosso país. Campos (2011) afirma que a imensa desigualdade existente no país também é fruto de reformas que não foram efetuadas no decorrer histórico como: a reforma agrária e a tributária. Somado a isso, em nosso país, a elite econômica e a elite política são coincidentes, tornando mais difícil a consolidação de mudanças que revertam esse quadro de desigualdades e de exclusões.

Em relação à situação do campo, as teorias sobre a modernização da agricultura tiveram como base a perspectiva liberal da economia que, por sua vez, se fundaram nos pensamentos de Adam Smith e Ricardo. Segundo Andrioli (2016), esses autores postulavam que somente através da divisão do trabalho (especialização crescente) e do comércio livre (mão invisível) seria possível um progresso econômico nas sociedades ${ }^{2}$. Sendo assim, para os teóricos da modernização, os agricultores tradicionais deveriam abandonar suas antigas práticas de diversificação, produção para autoconsumo, etc., e se especializarem cada vez mais em um único cultivo focando no aumento da produtividade com o auxílio do avanço das técnicas desenvolvidas pela ciência moderna. Dessa forma, para estes teóricos, agricultura e a sociedade como um todo não poderiam se desenvolver sem a ajuda das pesquisas técnicas e científicas realizadas nos centros acadêmicos (ANDRIOLI, 2016).

Tendo como pressuposto os ideais liberais, antropólogos e sociólogos passaram a interpretar em suas pesquisas o comportamento dos agricultores sem considerar as condições sociais, econômicas e culturais de cada realidade. Dessa forma, começam a defender a necessidade de uma mudança no comportamento desses sujeitos, que seria possível através dos serviços difusionistas, de transferência de tecnologias, de assistência técnica, ou seja, o saber tradicional, ancestral, desses agricultores passa a ser desvalorizado e visto como inferior aos conhecimentos desenvolvidos pela ciência moderna. E no caso da agricultura, isso significava ensinar a utilização de adubos químicos, sementes melhoradas, máquinas e técnicas de irrigação (ANDRIOLI, 2016).

Com base nessas teorias, na década de 1950, alguns autores no Brasil sustentavam que o país possuía

\footnotetext{
2 "A competição entre os concorrentes no livre-comércio, de acordo com as ideias liberais, faria com que os fatores de produção fossem utilizados de forma mais efetiva. Concentrando-se no que melhor pode produzir e ambicionando, exclusivamente, o lucro individual, cada produtor seria guiado pela "mão invisível" do livre mercado e, assim, contribuiria mais efetivamente para a prosperidade da comunidade" (ANDRIOLI, 2016, p. 48).
} 
uma economia natural ${ }^{3}$, baseada em complexos rurais (unidades de produção autônoma, onde não havia necessidade de consumo de insumos e manufaturas exteriores produzidos fora da propriedade) que não tinham alta produtividade e renda, mas eram autossuficientes. Para alguns intelectuais e políticos que estavam preocupados com o desenvolvimento econômico do país, esse complexo rural era um empecilho para a dinamização da economia, pois: não criava efeito multiplicador interno, não criava poder aquisitivo e demandas internas. Inviabilizava a industrialização (MIELITZ; MELO, 2010).

Sendo assim, seria necessário romper com a autossuficiência, promover a mecanização, oferecer crédito, especializar a agricultura e a indústria. Nesse sentido, podemos ver a constituição dos complexos agroindustriais substituindo os complexos naturais rurais, com forte apoio do Estado através das políticas públicas, para se realizar esta transição. Como exemplo, temos: a criação do sistema de crédito (1965), criação de institutos de pesquisa agropecuária (Embrapa, 1972), criação de um órgão de assistência técnica (Embrater), uma política de garantia de preços mínimos (PGPM) e o seguro agrícola (Proagro) (MIELITZ; MELO, 2010).

Com o objetivo de desenvolver o capitalismo em nossa nação, o Estado impôs o processo da modernização agrícola criando: a necessidade do campo consumir insumos que seriam produzidos no urbano (agrotóxicos, fertilizantes, máquinas, sementes laboratorialmente modificadas, irrigação artificial), a necessidade dos agricultores aprenderem como produzir com os técnicos

3 Esta é a visão de Gilberto Paim sobre a questão agrária brasileira: "Podemos entender o complexo rural como uma unidade de produção complexa em que as atividades produtivas e econômicas predominantes são as primárias, caracterizadas pela baixa produtividade, pela autossuficiência, por uma reduzida geração de renda, pela baixa capacidade de importar seus produtos e pela ausência de mercado interno com capacidade de consumir produtos manufaturados. Essa realidade é também chamada pelo autor de "economia natural". Os complexos rurais constituiam-se em unidades quase autossuficientes em relação ao restante do território e da economia nacionais, sendo sua única relação comercial com o exterior estabelecida através da compra de bens de luxo para as classes proprietárias e da venda de seu produto agrícola para o exterior. Seus primitivos meios de produção, tais como a alimentação para a força de trabalho escrava, embalagens rústicas, entre outros, provinham dos domínios da própria unidade. Esses estabelecimentos quase se bastavam, tendo mínima relação econômica com seu entorno, não criando, portanto, nenhum efeito dinamizador ou multiplicador das ações econômicas" (MIELITZ; MELO, 2010, p. 11). (Grifos meus). extensionistas (formados nos centros de pesquisa e ensino nos centros urbanos), a necessidade de financiamento para conseguir produzir nos novos moldes que eram ditados. Com isso, surge e aumenta cada vez mais a dependência que o rural tem do urbano.

Esse processo, como muitos estudos já comprovaram $^{4}$, levou ao aumento do êxodo rural (aglomeração nos centros urbanos, urbanização sem planejamento), desempregos, desestruturação comunitária, contaminações e intoxicações entre outras degradações ambientais e humanas. Dessa forma, esse modelo de desenvolvimento, adotado pelo Estado brasileiro, gerou mais concentração fundiária, maior concentração de renda, desigualdades sociais e, dessa forma, impulsionou também a formação dos movimentos sociais no campo.

Com a chegada do neoliberalismo na década de 1990, teremos a intensificação desse processo que passará a ser designado como agronegócio.

O emprego do termo "agronegócio" no Brasil ocorre a partir da última década do século $\mathrm{XX}$, quando entidades patronais vinculadas ao setor agrário e agroindustrial, como CNA - Confederação Nacional da Agricultura, OCB - Organização das Cooperativas do Brasil e Abag - Associação Brasileira do Agronegócio, passam a difundi-lo entre os associados, no mercado financeiro, nos órgãos governamentais e na mídia (HESPANHOL apud CAMPOS, 2011, p.104)

O agronegócio pode ser compreendido como uma "complexa articulação de capitais direta e indiretamente vinculados com os processos produtivos agropecuários", consolidado com o neoliberalismo, sob o controle de grupos multinacionais e que, "em aliança com o latifúndio e o Estado", propicia a acumulação capitalista gerando riqueza para poucos e pobreza para muitos. (CAMPOS, 2011)

O Estado foi um importante aliado para o fortalecimento do agronegócio: financiando ou realizando grandes obras em infraestrutura de transporte (rodoviário, ferroviário e portuário) e de energia, flexibilização de leis trabalhistas e ambientais; isenções ou grande redução de impostos para os produtos destinados à exportação,

4 Como exemplo, temos os estudos de Camarano e Abramovay (1999) e de José Graziano da Silva (2003). 
liberação do cultivo e comercialização de sementes transgênicas, empréstimos subsidiados para grandes grupos implantarem ou ampliarem empreendimentos, além da renegociação de dívidas e concessão de créditos a proprietários rurais. (Ibid, 2011)

Em âmbito nacional, a mesma política neoliberal que fomentou o agronegócio, realizou privatizações que resultaram no fechamento de 546 mil postos de trabalho no Brasil. "Ao longo da década de 1990, as politicas neoliberais destruíram 3,2 milhões de empregos assalariados formais" (POCHMANN, 2001, p. 29). No âmbito rural, segundo análise de Scheneider e Radomsky (2002), a intensificação do progresso tecnológico para os cultivos de grãos, sobretudo a soja transgênica, foi responsável pelo drástico aumento de desemprego no campo no RS, no período de 1992 a 1999. Já em relação às mulheres o impacto foi imenso: a taxa de desocupação das mulheres saltou de 34\% em 1981, pra 64\% em 2004 (CAMPOS, 2011).

Esse modelo de desenvolvimento atinge mais fortemente a vida das mulheres. Pois, aliado ao capitalismo, temos a cultura patriarcal, gerando marginalização e exploração crescente do sexo feminino. Existem feministas, como Heleieth Saffioti (1985, 2013), que corroboram com Engels (1984) em relação à origem do patriarcado: que esse teria surgido concomitantemente à origem da propriedade privada. Sendo assim, esta autora defende que o patriarcado e o capitalismo são duas faces de uma mesma moeda. A autora explica que é possível observar que, nas progressivas etapas da formação do capitalismo, o elemento que sempre esteve presente foi o patriarcado, independente dos diferentes modos de produção (escravista, feudal, capitalista). A supremacia masculina e a origem da propriedade privada seriam resultados de um mesmo processo histórico. Dessa forma, ela defende que é preciso pensar o patriarcado como componente intrínseco tanto ao escravismo, ao feudalismo, como ao capitalismo.

A ideia de que o patriarcado e o capitalismo são duas faces de uma mesma moeda, implica em que: o âmbito privado, onde ocorrem as relações sociais de reprodução, está influenciado e também influencia as relações sociais de produção (o espaço público). Nesse sentido, Saffioti (1985) defende que as contradições entre sexos e entre as classes sociais não são paralelas, mas sim cruzadas. Não é possível pensá-las isoladamente, mas em constante imbricação o tempo todo. Capitalismo e patriarcado seriam duas faces inseparáveis, atuando como sistemas de dominação social, cultural, política e econômica. O patriarcado não estaria relacionado apenas aos aspectos sociais, culturais e políticos, enquanto o capitalismo se caracterizaria pela dominação econômica. Os dois atuam conjuntamente em todas as esferas da sociedade, ou seja, tanto na produção, como na reprodução.

Os fundamentos do patriarcado já estavam dados na formação dos estados arcaicos e as relações de domínio do homem na sociedade estão expressas nas primeiras leis escritas. Posteriormente, isso foi "imortalizado" com o advento do monoteísmo judaico-cristão e justificado filosoficamente na Grécia Antiga. A partir disso, essa cultura se manteve e se reproduziu no decorrer dos séculos mantendo a posição subordinada das mulheres, apesar da resistência destas. Com o surgimento da ciência moderna não será diferente, as mulheres continuarão sendo vistas como seres inferiores intelectual e moralmente e as teorias científicas farão o esforço para provar isto (LERNER, 1985).

Segundo Saffioti (2013), as relações sociais possuem uma dimensão econômica que no mundo pré-capitalista era ocultada na desigualdade de status jurídico dos homens (livre, servo, escravo), mas que na sociedade capitalista passa a ser desnudada: "É como livres possuidores de sua força de trabalho que eles participam do mercado" (idem, 2013, p. 54). Isto levaria à ilusão de que as capacidades individuais, de cada um, eram responsáveis por suas realizações pessoais, pelo seu enriquecimento ou empobrecimento, etc ${ }^{5}$.

\footnotetext{
5 Nas sociedades pré-capitalistas, o status de rei é adquirido por meio das guerras e estes nomeiam sacerdotes/sacerdotisas que fazem parte de sua família e esse status toma a aparência de status atribuído, sinal disso é quando este rei passa a ser identificado com um deus e as rainhas/sacerdotisas com deusas. Da mesma forma, o status de um escravo é adquirido em uma guerra ou pelo empobrecimento e, com o tempo, passa a ser visto como uma qualidade intrínseca da pessoa (vide Aristóteles que argumenta que uns nasceram para governar e outros para serem governados). O status atribuído, no capitalismo, diz respeito ao fato de que os capitalistas enriquecem não porque trabalham mais que os outros, ou seja, porque teriam adquirido este status, mas porque as condições históricas criaram uma sociedade de possuidores e despossuidores. O capitalista não é muito rico porque é mais esforçado ou possui capacidades especiais, mas porque explora o trabalho alheio (ou seja, é um status atribuído, oriundo da posição hierárquica que ele possui na sociedade, fruto de uma construção histórica).
} 
Dado que a estrutura de classes é altamente limitativa das potencialidades humanas, há que se renovarem, constantemente, as crenças nas limitações impostas pelos caracteres naturais de certo contingente populacional (...). Do ponto de vista da aparência não é a estrutura de classes que limita a atualização das potencialidades humanas, mas, ao contrário, a ausência de potencialidades de determinadas categorias sociais que dificulta e mesmo impede a realização plena da ordem social competitiva (SAFFIOTI, 2013, p. 59).

A mulher possui uma herança histórica que lhe marca a face, o corpo, a mente, como sendo um ser inferior, com potencialidades e capacidades inferiores às dos homens. Mas, isso tudo não é visto como um status atribuído (construído historicamente), mas sim como adquirido, a mulher é mais explorada na sociedade capitalista ou não "evolui" nela porque ela produziria menos, seria menos competente, por razões biológicas de seu sexo. A sociedade capitalista se apropria da cultura criada historicamente para se manter viva e com a aparência de igualdade que lhe dá sustentação ideológica.

Via de regra, no capitalismo as mulheres se tornam as responsáveis pela produção de valor de uso, enquanto os homens ficam responsáveis pela produção com valor de troca (VIEZZER, 1989), ou seja, as mulheres ficam responsáveis pelos trabalhos do âmbito privado, doméstico, não remunerado, enquanto aos homens ficam destinados os assuntos públicos e o trabalho remunerado. Dessa forma, por não ser remunerado, o trabalho da mulher se torna invisível e é desvalorizado. E o trabalho do homem se torna o único valorizado por ser este o que gera riqueza monetária para a família e a sociedade. Sendo assim, não se percebe que, para que seja possível o trabalho produtivo, é imprescindível a existência do trabalho reprodutivo (cuidado dos filhos, preparo de alimentos, etc.).

Com isso, as mulheres permanecem dependentes dos homens, já que não possuem autonomia econômica, financeira. Dessa forma, as mulheres se mantêm reféns do autoritarismo masculino sendo que dependem dos homens para poder sobreviver. E quando ousam se separar de seus maridos ou são rejeitadas por esses, enfrentam a miséria e a pobreza tendo em vista que este sistema, que diz dar oportunidade a todos, limita, em muito, o acesso das mulheres aos cargos de trabalho ${ }^{6}$.

Sendo assim, podemos dizer que com o capitalismo surge uma dicotomia: o trabalho público (produção) e o trabalho privado (reprodução). O primeiro sendo realizado pelos homens e altamente valorizado. E o último destinado às mulheres e sendo altamente desvalorizado. $\mathrm{O}$ primeiro representando o valor de troca, o segundo o valor de uso. O primeiro representando o mundo dos negócios e da cultura, o segundo o mundo do lar, da casa, da natureza. Ou seja, há uma desvalorização crescente a tudo o que diz respeito ao privado, à mulher, ao valor de uso, à casa (e aqui podemos entender a própria natureza). As coisas passam a ter valor apenas em relação ao seu valor de troca. O trabalho que os homens passam a desenvolver está focado apenas nisso. Enquanto a mulher continua prezando pelo valor de uso.

Essa dicotomia é prejudicial, não apenas em relação à condição feminina na sociedade, mas, à sociedade como um todo, quando as qualidades e os trabalhos que são referidos às mulheres passam a ser desvalorizados: o valor de uso, o cuidado com a natureza, o lado emocional e afetivo dos seres humanos, etc.

Nesse sentido, temos reflexões feitas pelo próprio Marx de como as relações de produção capitalistas geram uma fratura irreparável no metabolismo social ${ }^{7}$ (MARX, 1996a). O fluxo

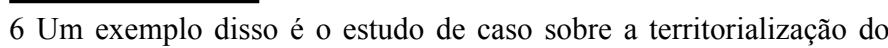
agronegócio em Cruz Alta/RS, de Christiane Senhorinha Soares Campos (2011), que evidenciou "a face feminina da pobreza em meio à riqueza do agronegócio". Já é sabido que o agronegócio, através da concentração das terras e com o uso de técnicas modernas de produção, diminui o número de empregos onde se aloca, com isso, gerando pobreza. O que foi revelado nesse estudo é que os empregos gerados pelo agronegócio são masculinos (apenas 22\% dos postos de trabalho são ocupados pelas mulheres), formais, temporários ( $66 \%$ dos empregos são oferecidos por três meses) e precário devido à baixa remuneração e curto período de tempo da ocupação. As mulheres ocupavam menos postos de trabalho nos empregos fixos e nos temporários, as mulheres ocupam cargos sem poder de tomada de decisão, a média salarial feminina fica abaixo da média salarial masculina. Sendo assim, percebemos que em relação à geração de empregos o agronegócio acaba sendo ainda mais nocivo para as mulheres.

7 Marx introduz este conceito de metabolismo social para explicar as relações que se estabelecem entre homens e natureza: o homem através de suas ações regula e controla o metabolismo que ocorre entre ele e a natureza.

"Antes de tudo, o trabalho é um processo entre o homem e a Natureza, um processo em que o homem, por sua própria ação, media, regula e controla seu metabolismo com a Natureza. Ele mesmo se defronta com a matéria natural como uma força natural. Ele põe em movimento as forças naturais pertencentes a sua corporalidade, braços e pernas, 
econômico está essencialmente ligado ao fluxo ecológico, pois é da natureza que se retira os recursos que serão reelaborados na economia através do trabalho humano, e dependendo da forma que se faz isso, é possível gerar equilíbrio ou desequilíbrio. No capitalismo o valor que reina é o valor de troca, em busca da infinita acumulação de capital, ao invés do valor de uso. Um exemplo disso é como a agricultura no capitalismo não é ditada pelas necessidades reais, autênticas, de uso da população e da sustentabilidade do sistema, mas sim pelo mercado: os cultivos dependem das flutuações de preços no mercado, são ditados pelos benefícios monetários imediatos (MARX, 1996a).

É nesse sentido que Marx defendia a tese de que o capitalismo seria incapaz de gerir de forma racional a natureza ${ }^{8}$, apesar de todo o avanço científico e tecnológico, pois o capitalismo é incapaz de conservar as condições necessárias para a reciclagem dos elementos constitutivos desta, já que seu objetivo é o valor de troca e não trabalha na perspectiva da conservação do equilíbrio ecológico dinâmico do sistema, e sim na perspectiva de qual meio gera mais lucro.

E cada progresso da agricultura capitalista não é só um progresso na arte de saquear o trabalhador, mas ao mesmo tempo na arte de saquear o solo, pois cada progresso no aumento da fertilidade por certo período é simultaneamente um progresso na ruína das fontes permanentes dessa fertilidade. (...) Por isso, a produção capitalista só desenvolve a técnica e a combinação do processo de produção social ao minar simultaneamente as fontes de toda a riqueza: a terra e o trabalhador ${ }^{9}$ (MARX, 1996b, p.133).

cabeça e mão, a fim de apropriar-se da matéria natural numa forma útil para sua própria vida. Ao atuar, por meio desse movimento, sobre a Natureza externa a ele e ao modificá-la, ele modifica, ao mesmo tempo, sua própria natureza (MARX, 1996a, p. 297).

8"The moral of history, also to be deduced from other observations concerning agriculture, is that the capitalist system works against a rational agriculture, or that a rational agriculture is incompatible with the capitalist system (although the latter promotes technical improvements in agriculture), and needs either the hand of the small farmer living by his own labour or the control of associated producers" (MARX, 1996c, p. 83).

9 Marx desenvolve uma crítica à exploração capitalista da natureza em relação ao roubo dos nutrientes do solo, sem conservar seus meios de reprodução. Ele ataca o latifúndio como responsável por expulsar a população do campo, criando os "inchaços" nas cidades e, com isso, a própria fratura no metabolismo social que leva à diminuição da vitalidade do solo. Nesse sentido, ele afirma que enquanto nas cidades as indústrias exploram os trabalhadores, no campo o latifúndio explora a terra. A produção capitalista se desenvolve explorando e destruindo as fontes de toda a riqueza: o solo e os trabalhadores (MARX, 1996b).
Sendo assim, podemos observar como o capitalismo, se apoiando na herança da cultura patriarcal, tem legitimado ideologicamente a exploração das mulheres, da natureza, e também de tudo o que diverge dos interesses do centro hegemônico de poder, como classes sociais, etnias e povos/culturas diversos/as. Por outro lado, podemos observar também, que este não é um processo pacífico. Pois, as populações atingidas por essas explorações e opressões reagem, se unem e passam a formar os chamados movimentos sociais. E as mulheres, como foi visto, sendo uma das categorias mais atingidas por este modelo civilizatório excludente, passam a se organizar e a criar movimentos de lutas próprios, com suas bandeiras específicas, buscando dar visibilidade para problemas milenarmente ocultados e que se aprofundam no sistema capitalista. E é neste contexto que vemos surgir as raízes do Movimento de Mulheres Camponesas do Paraná, que começaremos a analisar no próximo item.

\section{Raízes dos Movimentos de Mulheres no Paraná: o MPMP}

A partir de entrevista com a dirigente do $\mathrm{MMC} /$ $\mathrm{PR}$, Sandra, ela nos conta que as raízes do MMC/PR estão no Movimento Popular de Mulheres do Paraná (MPMP), que este seria o primeiro movimento de mulheres trabalhadoras rurais no PR que ela tem conhecimento e que teria sido este o movimento que fez parte das articulações que futuramente dariam origem ao MMC/PR.

O MPMP surgiu em 1981 e contou com a participação de mulheres tanto urbanas como rurais de todas as regiões do estado. Este movimento realizava trabalhos de conscientização, formação e capacitação de mulheres, para que essas resgatassem sua autoestima, cidadania e se tornassem protagonistas de suas vidas. Com isso, buscando a construção de uma sociedade igualitária, com outro projeto político de sociedade (KNAPIK, 2005).

$\mathrm{Na}$ década de 1970 as mulheres começaram a participar dos Clubes de Mães e das Comunidades Eclesiais de Base $^{10}$ (CEBs). Nesses espaços era comum o estudo

10 As Comunidades Eclesiais de Base surgiram na década de 1950, tomam força a partir do Concílio Vaticano II e se inserem nas lutas com os movimentos sociais na década de 1960. Elas começaram na área rural e depois avançam para a urbana. Segundo Knapik (2005), elas surgem com alguma atividade solidária de um pequeno grupo inspirado no Evangelho, por ação de algum agente pastoral. Nas CEBs 
da bíblia, o artesanato e a discussão sobre os problemas da comunidade. Knapik (2005) conta que as mulheres participavam desses espaços por ser uma atividade social, onde elas poderiam interagir com outras mulheres e conversar sobre suas vidas fugindo da solidão da vida de dona de casa, possibilitava a abertura de novos horizontes escapando da rotina e podendo aprender diversas coisas como artesanato, cuidados com a saúde, etc. Através das pastorais, das experiências de base, essas mulheres incorporam discussões políticas e econômicas em seus encontros.

A Comissão Pastoral da Terra (CPT) teve grande influência no processo da formação do MPMP. A CPT surge em junho de $1975^{11}$ ligada à Igreja Católica. Com isso, adquiriu caráter ecumênico, tanto no sentido dos trabalhadores que eram apoiados, quanto na incorporação de agentes de outras igrejas cristãs, como a Igreja Evangélica de Confissão Luterana no Brasil - IECLB. Ela foi criada para estar a serviço da causa dos/as trabalhadores/ as do campo e de ser um suporte para a sua organização. São estes/as trabalhadores/as que definem os rumos a seguir, seus objetivos e metas. A CPT os acompanha com espírito crítico. Nesse sentido, a CPT atuou na luta pela Reforma Agrária, dos Atingidos por Barragens, pelos direitos humanos e também na luta pela valorização e libertação da mulher camponesa (CPT, 2010).

Em 1981, agentes da Pastoral, que realizavam trabalhos com mulheres, organizaram um encontro para gerar uma formação mais ampla e discutir temas como: participação nas organizações sociais, questões específicas das mulheres, e como transformá-las em sujeitos de sua própria libertação. Pois, percebiam que os Clubes de Mães não estavam avançando em algumas discussões. Em novembro deste mesmo ano é realizado o primeiro Encontro de Mulheres, em Francisco Beltrão (com mulheres de Castro, Medianeira, Curitiba, Capanema e Turvo), com o

se realizavam reuniões frequentes para rezar, refletir sobre assuntos da Bíblia e problemas da comunidade. Knapik (2005) revela que as discussões eram baseadas no método de Ver (relacionar os fatos com as causas, ver a realidade de forma crítica), Julgar (contrastar a realidade com os valores cristãos) e Agir (ação concreta sobre o que foi visto e julgado. O que pode ser feito?).

11 Durante o Encontro de Bispos e Prelados da Amazônia, convocado pela Conferência Nacional dos Bispos do Brasil (CNBB). Em plena ditadura militar, ela nasce como resposta à grave situação vivida pelos trabalhadores rurais, posseiros e peões, em especial na Amazônia, explorados em seu trabalho e expulsos das terras em que viviam (CPT, 2010). objetivo de discutirem uma metodologia e a problemática do trabalho com as mulheres, além de conscientizarem as mulheres de seu valor e que estas começassem a sair para a luta. É aí que surge o MPMP e que vai abranger as sete regiões do estado (Sul, Oeste, Região Metropolitana, Sudoeste, Centro, Norte e Nordeste) (KNAPIK, 2005).

Cada região apresentava seu contexto e problemas específicos sendo que na maioria delas, com exceção da região metropolitana, eram as mulheres rurais que faziam parte do movimento. Nessas diferentes regiões, diferentes realidades se somavam para a construção do movimento: situação dos boias-frias nos latifúndios, salários menores para as mulheres, ocupação de terras, sindicalização, tribos indígenas, construção da barragem de Itaipu, entre outras $^{12}$.

O MPMP funda-se baseado em três objetivos centrais, dos quais se destrincham tantos outros: “a) a importância de a mulher começar a dar valor a si mesma; b) conscientizar homens e mulheres do modo como a exploração e subordinação da mulher contribui e é fundamental para a manutenção do sistema capitalista; c) formular o projeto de uma sociedade nova" (KNAPIK, 2005, p. 93).

Como estratégia de trabalho, o MPMP dividiu as tarefas e interesses do movimento em Bandeiras de Luta: equipes foram criadas para que os diferentes temas fossem desenvolvidos. Quando as mulheres ingressavam no movimento elas escolhiam a bandeira na qual iriam atuar. As práticas de formação eram feitas através dessas "bandeiras". Em 1985 também foi criada uma coordenação estadual. A princípio as primeiras bandeiras foram quatro: Mulher e Bíblia; Mulher e Sindicato; Mulher e Constituinte e Política; Mulher e Saúde. Em 1993 foram criadas mais três: Mulher e Educação; Mulher e Meio Ambiente; Mulher e Autossustento (KNAPIK, 2005).

Uma das bandeiras de luta que marcou muito o MPMP e que está relacionada com sua origem nas CEBs e CPT é a bandeira "Mulher e Bíblia", onde as mulheres se reuniam para fazerem uma releitura da Bíblia a partir de uma perspectiva feminina, trazer a face feminina, oculta, de Deus. Com base nos estudos de algumas teólogas

12 É interessante destacar que já em 1970 existiam grupos de mulheres. Em Medianeira elas fundam o Centro Popular de Saúde Yanten, que buscava realizar trabalhos com medicinas alternativas. 
mulheres $^{13}$, essas mulheres reinterpretavam diversas passagens da Bíblia desconstruindo o simbolismo desfavorável à mulher. A ideia era gerar uma autoestima nas mulheres, que desde sempre foram ensinadas que eram inferiores e submissas aos homens. Que elas passassem a se descobrir como sujeitos da sociedade. Todavia, apesar dessa bandeira ter sido a porta de entrada da maioria das militantes no movimento, ela se mostrou limitada na luta pelos direitos das mulheres (idem).

Segundo a fala de uma das integrantes do movimento, é possível aproveitar a instituição Igreja só até certo ponto, mas há um limite, pois ela não consegue extrapolar para além da estrutura que ela mesmo cria (KNAPIK, 2005, p. 119). Aqui a militante faz referência ao fato de que nessas discussões, apesar de se construir a consciência de que mulheres e homens têm direitos e deveres iguais, se mantêm o estereótipo das mulheres como seres que devem ser sensíveis, meigos, delicados e sempre as responsáveis pelo lar e tendo como função também a procriação de filhos ${ }^{14}$.

$\mathrm{Na}$ bandeira "Mulher e Sindicato" era feita a discussão e luta pelo reconhecimento da profissão de agricultora, de seus direitos específicos e do direito de sindicalização que ainda era barrado em alguns sindicatos para as mulheres. Além disso, se realizavam formações para que as mulheres pudessem alcançar as direções em seus sindicatos. Em 1990, lideranças do MPMP ingressam na CUT e se desligam do movimento. Por outro lado, essas lideranças formam a Comissão das Mulheres Trabalhadoras Rurais no Departamento Estadual de Trabalhadores Rurais, que vai se articular com o MPMP (KNAPIK, 2005).

A bandeira "Mulher e Política e Constituinte" surge devido ao debate sobre a elaboração da Constituição Federal que estava ocorrendo no país na década de 1980. Dessa forma, se discutia sobre os direitos das mulheres que deveriam estar presentes na Constituição. Eram realizadas formações de política, informando sobre os direitos e deveres, entre outros. Buscava também promover a

$13 \mathrm{Na}$ década de 1980 surge a Teologia Feminina, a partir da Teologia da Libertação. É a releitura dos textos bíblicos feita por teólogas mulheres.

14 As divergências ideológicas entre as integrantes do MPMP, uma mais conservadoras, outras mais progressistas, será um dos motivos do fim do movimento na década de 1990. A discussão sobre o aborto, segundo Knapik (2005), era sempre muito conflituosa. eleição de candidatas mulheres.

A bandeira "Mulher e Saúde" tratava de questões como sexualidade, gravidez, parto, planejamento familiar, convivência do casal, saúde alternativa, política de saúde para mulher, etc. Buscava gerar a consciência sobre o próprio corpo, assim como, resgatar práticas antigas realizadas pelas mulheres de cura: ervas medicinais, xaropes, pomadas, etc. Era o resgate do poder da mulher. Além disso, o tema da esterilização era muito discutido já que na década de 1970 houve uma esterilização em massa, feita nas mulheres, impulsionada pelo Estado. Já o aborto era um tema muito polêmico e evitado no movimento.

As outras bandeiras criadas em 1993 discutiam Educação (alfabetização através do método Paulo Freire, creches, etc.), Meio-Ambiente (direitos de reprodução, alimentação saudável, agricultura alternativa, reciclagem, etc) e Autossustento (independência financeira).

Das conquistas desse movimento temos a transformação das mulheres que passam a fazer parte dele, que geram processos de conscientização e conhecimento de si, que as permitem tornarem-se sujeitos e intervirem na realidade. Nesse sentido, a voz da mulher passa a ser ouvida nos mais diferentes espaços: na família, na igreja, no sindicato, nos partidos políticos, comunidades, etc. Essas mulheres adquiriram coragem para denunciar, reivindicar e transgredir normas e valores que as discriminavam e oprimiam (KNAPIK, 2005).

\section{A Articulação com os outros Movimentos de Mulheres do Sul}

Na década de 1980 surge a Articulação dos Movimentos de Mulheres Trabalhadoras Rurais dos Cinco Estados do Sul, que além de contar com movimentos de mulheres trabalhadoras rurais dos três estados do Sul, ainda abrangia movimentos de São Paulo e Mato Grosso do Sul. As organizações que fizeram parte dessa articulação foram: Organização de Mulheres Agricultoras de Santa Catarina (OMA); Organização de Mulheres Agricultoras de Mato Grosso do Sul; Movimento de Mulheres do Movimento Sem Terra do Estado de São Paulo; Movimento de Mulheres Trabalhadoras Rurais do Rio Grande do Sul; Comissão de Mulheres Trabalhadoras Rurais do Departamento Rural da CUT do Paraná (vinculada ao MPMP). 
Podemos resgatar algumas informações sobre essa Articulação a partir de uma cartilha escrita por ela na década de $1980^{15}$. Esta cartilha foi publicada no 8 de Março e tinha como título: Não importa onde estiver, sempre mulher. Ela continha dois objetivos: contribuir com a discussão sobre a saúde da mulher e sobre a previdência social.

$\mathrm{Na}$ discussão sobre a saúde, o texto parte de questionamentos da base: conhecer a real situação da saúde da mulher, levantar denúncias de casos que ocorrem nos municípios das militantes para, então, encaminharem propostas concretas, fazerem mobilizações e pressionar as autoridades para a garantia dos direitos das mulheres.

Além disso, essa publicação traz informações sobre o PAISM (Programa integral à Saúde da Mulher), mas alerta que este tem sido implementado em poucos municípios. Fala de cobrar a capacitação de técnicos da saúde para trabalharem especificamente com as mulheres; amparo e assistência na gravidez; garantia da licença maternidade. E por fim, "precisamos, unidas e em conjunto com toda a classe trabalhadora, exigir do governo melhores condições de vida e trabalho para a população, reivindicando emprego, casa, educação, salário decente, creche para as crianças e uma completa assistência à saúde" (AMMTR-SUL, p. 7).

Neste material essa articulação defende que a luta por melhores condições de saúde é uma ferramenta para o trabalho político de transformação social. E que essa luta só se fortalece quando as várias companheiras tomam consciência de suas dificuldades e passam a lutar coletivamente. Nesse sentido, elas enfatizam a importância das discussões e organização nos núcleos de base.

Na discussão sobre a Previdência, o objetivo era divulgar o que já tinha ocorrido, o que foi aprovado, as dúvidas que ficaram e o que ainda faltava concretizar. Nesta cartilha divulga-se, entre outras coisas, que o novo Plano de Benefícios da Previdência Social foi aprovado após muita luta política e embate entre as propostas do governo e as dos movimentos sociais e sindicatos. Uma das conquistas foi estabelecer os pequenos produtores rurais (marido, esposa e filhos maiores de 14 anos) como segurados especiais. Para aposentar os pequenos

15 As publicações das Articulações como as do MMC foram todas adquiridas durante uma visita ao Centro de Formação Maria Rosa, do $\mathrm{MMC} / \mathrm{SC}$, em Chapecó/SC. Infelizmente algumas delas não contém data de publicação. produtores não precisam ter um tempo de contribuição, apenas comprovar que trabalham no meio rural por pelo menos cinco anos. Mas alguns direitos reivindicados não foram conquistados e nessa cartilha as militantes convocam todas as companheiras para acompanharem de perto os acontecimentos, terem clareza do que foi aprovado e do que precisava ainda ser conquistado para que as pressões e mobilizações se intensificassem.

Nesse sentido, percebemos através dessa Articulação, nesse período histórico, que os movimentos de mulheres trabalhadoras rurais possuíam uma pauta em comum: a luta pela saúde, pela previdência, pela valorização da mulher na sociedade.

Em 1988 ocorre a mudança do nome da Articulação. A agora denominada Articulação de Instâncias de Mulheres Trabalhadoras Rurais do Sul ${ }^{16}$ (AIMTR-SUL) que irá contar com Instâncias dos três estados do Sul: PR, SC e RS. Além disso, o movimento de mulheres autônomas do estado de Mato Grosso do Sul também se manteve nessa articulação. $\mathrm{O}$ movimento de mulheres trabalhadoras rurais do PR que fez parte dessa articulação foi o MPMP. Tanto que a primeira secretaria dessa Articulação teve sede em Curitiba/PR.

Tivemos acesso a uma cartilha escrita por essa Articulação de 1996. Também publicada no 8 de Março, foi intitulada de Mulher Construindo a Cidadania, ela buscava recordar a história das conquistas e a participação da mulher na sociedade, para com isso, envolver as mulheres nesse processo para fortalecer o 8 de Março como dia de luta, denúncia e mobilização. Dessa forma, este material traz temas como o neoliberalismo, a situação da mulher neste contexto, os problemas do uso de agrotóxicos para a saúde, aumento da violência doméstica e da prostituição. Em seguida, o texto trata sobre a história de como os direitos das mulheres foram conquistados, de forma muito lúdica, em quadrinhos:

A partir de 1982/83, nós mulheres trabalhadoras fomos tomando consciência de nossa condição de discriminação,

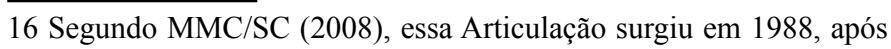
uma reunião nacional de mulheres trabalhadoras rurais do Brasil que ocorreu em Baurueri/SP, onde se deliberaram pelo fortalecimento dos movimentos nas diferentes regiões. Dessa forma, para avançar na luta e aprofundar questões como sexualidade, reconhecimento da profissão, reprodução, gênero, violência contra as mulheres, a partir da realidade da região sul, formou-se a Articulação de Instâncias de Mulheres Trabalhadoras Rurais do Sul. 
não só enquanto classe trabalhadora, mas também, enquanto mulher, corpo, sexualidade. Passamos a desenvolver lutas específicas: pelo reconhecimento de nossa profissão, pela aposentadoria, em busca de direitos enquanto mulher e cidadã (saúde, educação...) e em busca de nossa libertação na família, na comunidade, na sociedade (AIMTR-SUL, 1996, p. 8).

Em seguida a cartilha fala que em 1986, as militantes fizeram muitas mobilizações, manifestações, abaixo-assinados e viagens até Brasília, o que as tornou conhecidas e reconhecidas. Em 1988, contam que garantiram a aposentadoria aos 55 anos para as mulheres e 60 para os homens; e garantiram: auxílio-acidente de trabalho, auxílio doença, aposentadoria por invalidez, pensão de viúvas e o salário maternidade. Elas lembram das lutas que foram feitas para a regulamentação desses direitos e a colocação deles em prática, como o das primeiras aposentadorias para as trabalhadoras rurais e o salário maternidade.

Além disso, a cartilha fala da união que foi construída com outros movimentos na luta de classes, por política agrícola, reforma agrária, etc. Nessa época as militantes enfatizam a importância de se lutar por outro projeto de desenvolvimento para a agricultura familiar: "Um desenvolvimento com preservação da natureza, com respeito à terra, à vida, aos animais e à água. Um projeto que valorize as pessoas que trabalham e produzem" (AIMTR-SUL, 1996, p. 12).

Por fim, esta publicação de 1996, debate também questões como política e poder, a participação política da mulher na sociedade e a importância dessa participação.

Em 1995 é consolidada a Articulação Nacional de Mulheres Trabalhadoras Rurais (ANMTR), a partir do Encontro de Mulheres Trabalhadoras Rurais, realizado em outubro deste mesmo ano. A realização deste encontro, por sua vez, foi um encaminhamento tirado no I Congresso Latino Americano das Organizações do Campo, ocorrido no Peru, organizado pela CLOC (Coordenação Latino Americana de Organizações do Campo) onde foram discutidas as consequências do neoliberalismo para o campo (MMC/SC, 2008). Dessa forma, constrói-se um espaço de unificação das lutas, das discussões e mobilizações.

Em 2001, temos uma cartilha, da Articulação Nacional de Mulheres Trabalhadoras Rurais (ANMTR-
Brasil), intitulada: Nenhuma Trabalhadora Rural Sem Documento. Nela é exposto o objetivo da Articulação:

Articular os Movimentos de Mulheres Autônomas e os coletivos de gênero de todos os movimentos sociais do campo. Surgiu da necessidade das próprias mulheres e constitui-se num espaço de ação em função da problemática vivida pelas mulheres trabalhadoras rurais. Busca contribuir para as mudanças das relações sociais de gênero e de classe (ANMTR, 2001, p. 2).

Nesta cartilha, muito lúdica também, feita em quadrinhos, fala-se sobre a importância da mulher na sociedade e sua desvalorização, sobre o processo de dominação dos homens em relação às mulheres, com isso, busca enfatizar a importância e necessidade das mulheres agricultoras se identificarem como trabalhadoras rurais, valorizarem sua profissão e adquirirem seus documentos para garantirem os seus direitos. Ela busca incentivar discussões que revelem como as mulheres são discriminadas em todos os âmbitos da sociedade e entender porque é dado tão pouco valor para o trabalho das mulheres. Fala sobre as lutas e conquistas realizadas e da importância de se ter os documentos para que esses direitos conquistados possam ser colocados em prática. Explicam detalhadamente sobre todos os documentos, para que servem e como podem ser feitos.

\section{A Formação da OMTR}

Em entrevista com a dirigente do MMC/PR, Sandra, ela informa que O MPMP foi se desfazendo no início da década de 1990, devido às articulações das mulheres urbanas com as organizações urbanas, e, com o fortalecimento das mulheres rurais na AIMTR havia a demanda da formação de um movimento que representasse especificamente as mulheres do campo, com suas necessidades específicas. Foi se organizando, então, um movimento autônomo de mulheres trabalhadoras rurais no Paraná.

Dessa forma, em 1996 surge a Organização de Mulheres Trabalhadoras Rurais do Paraná (OMTR), um ano após a formação da Articulação Nacional de Mulheres Trabalhadoras Rurais, com isso a OMTR passa a fazer parte dessa articulação, como um movimento autônomo de mulheres rurais do Paraná. 
A OMTR passa a construir sua identidade própria, com suas simbologias e significados próprios. Sua bandeira apresentava uma mulher amamentando seu filho no meio da roça com uma araucária no fundo e com o seguinte lema: "a nossa história a gente faz".

A secretaria da OMTR foi fixada em São Mateus do Sul, região sul do Paraná. Lá as mulheres se organizavam para construírem processos de formação de base, de mobilizações, manifestações, etc.

\section{A Formação do MMC-Brasil}

Segundo Sandra, com a consolidação da Via Campesina, como instância de articulação dos diversos movimentos sociais do campo a ANMTR passa a ser um espaço de articulação dos movimentos autônomos de mulheres do Brasil, percebe-se, então, que precisa se consolidar um movimento de mulheres do campo, sendo que uma articulação maior de movimentos já estava sendo consolidada. Nas palavras de Sandra: "E com a consolidação da Via Campesina no Brasil, o espaço de articulação passou a ser a Via Campesina, não havia porque ter duas articulações. Essa articulação passou a se dar dentro da Via Campesina e os movimentos autônomos sentiram a necessidade de se consolidar como movimento".

Os diversos movimentos autônomos de mulheres trabalhadoras rurais possuíam lutas e pautas muito semelhantes, mas cada um tinha bandeiras, lemas, diferentes. Havia a necessidade de uma identidade que unisse esses movimentos no Brasil como um todo.

Dessa forma, em 2004 ocorre o Congresso de consolidação do MMC- Brasil (Movimento de Mulheres Camponesas do Brasil), de 05 a 08 de Março, com a participação de 1.400 mulheres de 14 estados. Sandra conta que houve uma participação significativa de todos os estados na construção da simbologia, nos aspectos que unificavam todos os movimentos. Processo esse que se deu na preparação do congresso. Para esse momento de consolidação do movimento autônomo o Paraná enviou três ônibus com militantes de diversas cidades do estado: Medianeira, Serranópolis do Iguaçu, Santa Helena, Ouro Verde do Oeste, Matelândia, Missal, Itaipulândia, Bom Jesus do Sul, São José das Palmeiras, Pitanga, Boa Ventura do São Roque, São Mateus do Sul, Bituruna, São João do Triunfo, Turvo, etc.
Nesse momento, assuntos como soberania e segurança alimentar tornam-se fundamentais em suas lutas. Sendo assim, a crítica ao atual modelo agrícola nacional focou-se na crítica ao uso de agrotóxicos, nas dificuldades criadas para se ter o controle das sementes, contra o plantio e consumo de alimentos transgênicos, em defesa do meio ambiente, sementes crioulas e florestas nativas (BONI, 2012).

Em entrevista feita por Paulilo (2007) a uma das lideranças do MMC, Adélia Schmitz, esta explica como funciona a organização do movimento: a discussão começa na comunidade, na base, depois há a Assembleia Municipal, seguida da Regional, Estadual e, por fim, da Nacional. É nas Assembleias Estaduais que se tiram as linhas que serão prioridades de trabalho por três anos. Nesse sentido, existem as direções municipais, estaduais e nacionais. E também há a Direção Executiva.

Ainda segundo Dona Adélia (PAULILO, 2007), o MMC se reconhece como um movimento democrático, popular, classista, feminista, autônomo, de mulheres que trabalham no campo.

Nossa causa é a transformação da sociedade.
Por isso nós lutamos: por direitos sociais,
garantia de uma Previdência pública universal
e solidária, salário-maternidade. Foi uma
conquista nossa a aposentadoria da mulher
com 55 anos e homem, 60. [Lutamos por]
saúde pública integral com atendimento
humanizado para todas e todos, SUS, um
direito conquistado em lei; fim da violência
contra as mulheres da classe trabalhadora;
por uma agricultura camponesa com
políticas públicas na agricultura, produção
de alimentos saudáveis, soberania alimentar
e reforma agrária, crédito especial para as
mulheres, que é uma luta também; defesa,
preservação, multiplicação e conservação
da biodiversidade, e com monocultura a
biodiversidade vai desaparecendo; acesso
e garantia de documentos pessoais e
profissionais, bloco de notas de produtora
rural em todos os estados do Brasil, campanha
nacional de nenhuma trabalhadora rural sem
documentos (PAULILO, 2007, p. 407 ).

\section{O MMC/PR}

Após a unificação no MMC Brasil a coordenação estadual do MMC/PR (antiga OMTR) se manteve em São Mateus do Sul. Era para lá que eram enviadas todas as 
informações, as diretrizes e recursos para a realização de encontros, formações, etc. As coordenadoras responsáveis por essa secretaria eram integrantes do movimento desde a época do MPMP. Todavia, segundo Sandra ${ }^{17}$, ocorreu uma fragilização muito grande do movimento no Paraná devido a desvios éticos, políticos e financeiros, dessas coordenadoras na época. Diversas militantes que já estavam descontentes com alguns procedimentos se afastaram para sempre do movimento o que o enfraqueceu muito.

Em 2006, a coordenação nacional do MMC, que já estava percebendo alguns problemas com esta secretaria, decidiu se desvincular daquele espaço, associação, instituição e pessoas não reconhecendo mais como integrantes do MMC/BR. Essa decisão foi socializada com os diversos movimentos e organizações do Paraná e o MMC Brasil passou a ter apenas algumas pessoas como contato no estado.

Em março de 2007 o MMC Brasil fez o lançamento da Campanha Nacional pela Produção de Alimentos Saudáveis - CNPAS. No PR o lançamento foi feito no interior do município de Boa Ventura de São Roque, com mulheres de diversos municípios do Sudoeste e Centro do Estado.

As militantes do MMC do Paraná que permaneceram no movimento ficaram sem nenhuma estrutura e até hoje o movimento no estado não possui uma associação jurídica para poder escrever projetos, etc. Sandra conta que foi um período muito difícil.

De qualquer forma, pouco a pouco, as militantes do $\mathrm{MMC} / \mathrm{PR}$ que se mantiveram foram conseguindo fazer cursos de formação com recursos que vinham da Articulação Sul. Conseguiram encaminhar diversas jovens para fazer cursos de graduação: medicina em Cuba, agroecologia, pedagogia do campo, licenciatura em educação do campo, entre outros em parceria com os movimentos sociais e universidades no Brasil. Mesmo com muita dificuldade Sandra e outras companheiras conseguiram realizar cursos e projetos através do MMC: oficinas de compostagem, sal mineral homeopático, peletização de sementes, plantas medicinais, artesanato, e o projeto de construção de cisternas para contribuir nos

17 Sandra é co-autora deste artigo e também uma das entrevistadas para a formulação do mesmo, por ser uma das dirigentes do MMC/PR e ter acompanhado de perto todo o processo histórico da formação do MMC no estado do Paraná. quintais produtivos (foram construídas dez cisternas em quatro municípios do sudoeste do PR, sendo 2 em Ampere, 2 em Flor da Serra do Sul, 3 em Bom Jesus do Sul e 3 em Barracão (dá pra fazer nota de rodapé com os nomes dos municípios...). Sempre articulando o estudo e a pratica, dentro das propostas da CNPAS.

Um fortalecimento do Movimento no Paraná começa ocorrer através do trabalho de base feito em especial por Sandra, que em seu curso de graduação ${ }^{18}$ conseguiu atrair para o MMC mais uma companheira: Marinês Schreiber.

Marinês vive no Reassentamento São Francisco de Assis, em Cascavel/PR, reassentamento este que foi fruto de um longo processo de luta pelos atingidos pela barragem de Salto Caxias. Neste local, existiam grupos de mulheres que debatiam diversos assuntos como problemas da comunidade e relações de gênero, e que se iniciaram no processo de luta pela terra. Uma vez que Marinês se identificou com o movimento e passou a fazer parte dele, ela começa a fazer os processos de formação e levar esses conhecimentos para o seu grupo de mulheres no reassentamento. Dessa forma, ela consegue ir cativando outras companheiras para o MMC.

Rosângela, também moradora do reassentamento, que participou ativamente no processo de luta pela terra, consegue igualmente ingressar no curso de licenciatura em educação do campo, indicada pelo MMC, em anos posteriores. Dessa forma, quando ela entra no curso ela já se reconhece como sendo militante do MMC e vai contribuir no fortalecimento do movimento dentro do reassentamento.

Em entrevista com Marinês, ela conta que há pelo menos trinta mulheres no reassentamento hoje que se identificam com o movimento e estão bem engajadas na luta. Dessa forma, temos no reassentamento duas novas lideranças que se formam: Marinês e Rosângela, que passam a ser também dirigentes do MMC no PR.

Mesmo assim, Sandra afirma que existe ainda uma demanda muito grande de formação de dirigentes, de militantes que assumam funções mais organizacionais no movimento e de liderança. Atualmente existem apenas

18 Curso Especial de Pedagogia para Educadores do Campo. Turma II. Movimentos Sociais do Campo. Realizado através do Programa Nacional de Educação na Reforma Agrária - PRONERA. Na Universidade Estadual do Oeste do Paraná (UNIOESTE). Cascavel,em 2012. 
cinco dirigentes no estado (dos municípios de Flor da Serra do Sul, Barracão, Cascavel, São Jorge D’Oeste, Foz do Iguaçu e outras cidades do sudoeste do Paraná), sendo que muitas delas têm estado muito ocupadas com seus trabalhos e não têm podido atuar com mais intensidade no movimento.

Outro aspecto importante da entrada de Marinês e Rosângela para o MMC, assim como o de outras companheiras do reassentamento, foi a possibilidade de se ter um espaço físico para a realização dos processos de formação no estado do Paraná. No reassentamento, essas militantes conseguiram reformar uma antiga casa que estava abandonada para que se iniciassem encontros do movimento lá. Sendo assim, em 2015, ocorreu um processo de formação em parceria entre o MMC e a Universidade da Fronteira Sul (UFFS) ${ }^{19}$, "Organização Produtiva de Mulheres e Promoção de Autonomia por Meio do Estímulo à Prática Agroecológica", que teve grande parte de suas etapas realizadas neste espaço no reassentamento.

Diante deste trajeto percorrido pelo MMC, percebe-se alguns avanços significativos na vida das mulheres e de suas famílias, são exemplos perceptíveis, a mulher se reconhecer como agricultora/camponesa, auto valorização e também da agricultura como um espaço de construção de relações, de produção de alimentos saudáveis, de preservação das sementes crioulas, das plantas medicinais, do conhecimento popular e milenar das mulheres, do desenvolvimento ou fortalecimento de experiências com os princípios da agroecologia, espaço da biodiversidade. Outro elemento de mudança é reconhecer o campo como espaço de opção de vida e não como espaço de quem "não teve outra opção". Outra questão perceptível é que muitas mulheres que participaram ou participam do MMC buscam trabalhar a questão da autonomia econômica, diversificando e comercializando a produção em feiras, fazendo a venda direta, e/ou em programas institucionais como o PAA. As mulheres também se instrumentalizaram com conhecimento e informações acerca dos seus direitos (previdência, saúde, agricultura, violência...), cobrando dos órgãos públicos a implementação e cumprimento dos mesmos.

\section{Considerações Finais}

$\mathrm{O}$ que buscamos trazer aqui foi apenas um esboço do que foi a história do movimento de mulheres trabalhadoras rurais do Paraná até a formação do $\mathrm{MMC/}$ PR. Percebemos que sua trajetória é sinuosa, complexa e profunda e para ser compreendida melhor mereceria um estudo mais completo, com mais fontes bibliográficas e entrevistas. Todavia, o que almejávamos trazer aqui era apenas um mapa, de alguns caminhos que esses movimentos tomaram até chegar à formação do $\mathrm{MMC} /$ $\mathrm{PR}$, para que, em projetos futuros, aprofundamentos sejam feitos.

De qualquer forma, podemos ter a dimensão da força que foram esses movimentos e como eles contribuíram para a transformação da vida de tantas mulheres no Paraná. Tomamos consciência da potencialidade das mulheres paranaenses para as lutas, dessa forma, se alimenta a esperança de que o MMC/ PR se fortaleça cada vez mais no estado, se espalhando para mais regiões e transformando a vida de mais mulheres.

\section{Referências Bibliográficas}

AIMTR (Articulação de Instâncias de Mulheres Trabalhadoras Rurais - Sul) (1996). Mulher Construindo a Cidadania. Curitiba.

AMMTR-SUL (Articulação dos Movimentos de Mulheres Trabalhadoras Rurais dos Cinco Estados do Sul) (sem data). Não Importa Onde Estiver, Sempre Mulher.

ANDRIOLI, A. I. Soja Orgânica Versus Soja Transgênica: um estudo sobre tecnologia e agricultura familiar no noroeste do Estado do Rio Grande do Sul. Chapecó: UFFS, 2016.

ANMTR-BRASIL (Articulação Nacional de Mulheres Trabalhadoras Rurais do Brasil) (2001). Nenhuma Trabalhadora Rural Sem Documentos.

19 O MST e a FETRAF também fizeram parte desse projeto. 
BONI, Valdete (2012). De Agricultoras a Camponesas:o movimento de mulheres camponesas de Santa Catarina e suas práticas. Tese(Doutorado em Sociologia Política) - Programa de Pós Graduação em Sociologia Política da Universidade Federal de Santa Catarina. Florianópolis, mimeo.

CAMPOS, C. S. S; A Face Feminina da Pobreza em Meio à Riqueza do Agronegócio. Trabalho e Pobreza das Mulheres em Territórios do Agronegócio no Brasil - O caso de Cruz Alta/RS.Buenos Aires: CLACSO, 2011.

CARDOSO, Rosângela. Rosângela Cardoso: depoimento [abr. 2016]. Entrevistadora: Renata Rocha Gadelha. Cascavel: Reassentamento São Francisco, 2016. Entrevista concedida para pesquisa de mestrado de Renata Rocha Gadelha, do programa de pós-graduação em agroecologia e desenvolvimento rural sustentável da UFFS.

CIMA, Justina. Justina Cima: depoimento [abr. 2016]. Entrevistadora: Renata Rocha Gadelha. Chapecó: Sede do MMC/SC, 2016. Entrevista concedida para pesquisa de mestrado de Renata Rocha Gadelha, do programa de pós-graduação em agroecologia e desenvolvimento rural sustentável da UFFS.

CPT (Comissão Pastoral da Terra) (2010). Histórico. Disponível em: $<$ http://www.cptnacional.org.br/index. php/sobre-nos/histórico>. Acesso em: 29 Jun. 2016.

ENGELS, F. A Origem da Família, da Propriedade Privada e do Estado. $9^{\mathrm{a}}$ edição. Rio de Janeiro: Civilização Brasileira S. A., 1984.

FURTADO, C. Introdução ao Desenvolvimento. Enfoque Histórico-Estrutural. Rio de Janeiro: Paz e Terra, 2000.

KNAPIK, Márcia (2005). Movimento Popular de Mulheres do Paraná: 10 anos construindo a vida. $1^{\mathrm{a}}$ edição. Curitiba: Editora Gráfica Popular: CEFURIA.

LERNER, G.La Creación Del Patriarcado.Editorial Crítica, 1985.
MARX, K. O Capital. Volume 1. Tomo 1. São Paulo: Editora Nova Cultural, 1996a.

MARX, K. O Capital. Volume 1. Tomo 2. São Paulo: Editora Nova Cultural, 1996b.

MARX, K. O Capital. Volume 3. Versão online: Marx.org 1996c. Disponível em: www.marxists.org/archive/marx/ works/download/pdf/Capital-Volume-III.pdf. Acesso em: 04 de out. 2016.

MIELITZ, C.G.A; MELO, L.M; MAIA, C.M. Politicas públicas e desenvolvimento rural no Brasil. Porto Alegre: Editora da UFRGS, 2010.

MMC/SC (2008). Uma História de Organização, Lutas e Conquistas. Secretaria Especial de Políticas para Mulheres. Chapecó.

PAULILO, Maria; SILVA, Cristiane (2007).“A Luta das Mulheres Agricultoras: entrevista com Dona Adélia Schmitz". Estudos Feministas, n. 15, 240: p. 399-417, mai-ago.

POCHMANN, M. A Década dos Mitos. São Paulo: Contexto, 2001.

RODRIGUES, Sandra. Sandra Marli da Rocha Rodrigues: depoimento [jun. 2016]. Entrevistadora: Renata Rocha Gadelha. Foz do Iguaçu: casa da Sandra, 2016. Entrevista concedida para pesquisa de mestrado de Renata Rocha Gadelha, do programa de pós-graduação em agroecologia e desenvolvimento rural sustentável da UFFS.

SAFFIOTI, H. Força de Trabalho Feminina no Brasil: no interior das cifras.Perspectivas, São Paulo, 8:95-141, 1985.

SAFFIOTI, H. Gênero Patriarcado Violência. $2^{\mathrm{a}}$ ed. São Paulo: Expressão Popular: Fundação Perseu Abramo, 2015.

SCHNEIDER, S; RADOMSKY, G. OMercado de Trabalho Rural Gaúcho na Década de 1990: as transformações recentes. In: XXXIX Congresso da Sociedade Brasileira de Economia e Sociologia Rural, Recife, 5-8/8/2001. 
SCHEREIBER, Marinês. Marinês Schereiber: depoimento [abr.2016]. Entrevistadora: Renata Rocha Gadelha. Cascavel: Reassentamento São Francisco, 2016. Entrevista concedida para pesquisa de mestrado de Renata Rocha Gadelha, do programa de pós-graduação em agroecologia e desenvolvimento rural sustentável da UFFS.

VEIGA, J. E. Desenvolvimento Sustentável. O desafio do Século XXI. São Paulo: Garamond, 2006.

VIEZZER, M. O Problema Não Está na Mulher. São Paulo: Cortez, 1989.

Recebido em: 16/09/2016.

Aceito: 15/05/2017. 